\title{
A multidimensional approach to the well-being of the population of the states of Mexico
}

\author{
Amilcar O. Fernández Domínguez \\ and Denise Gómez Hernández
}

\begin{abstract}
This article adapts a multidimensional index of the well-being of the population in the Mexican States, based on the recommendations of the Commission on the Measurement of Economic Performance and Social Progress (CMEPSP). This study's contributions can be summarized in three key points: (i) factor analysis of principal components is used, to allow for different weights of dimensions; (ii) consideration is given to inequality of material well-being within the population of each state, and; (iii) representative state data are considered for all dimensions. The results show that the dimensions of objective well-being have greater weights than the dimensions of subjective well-being, and that differences between weights of dimensions and indicators used are more important than their quantity or characteristics.
\end{abstract}

\section{Keywords}

Social welfare, measurement, statistical methodology, economic development, social development, development indicators, Mexico

JEL classification

131, O54, C38, C43

Authors

Amilcar Orlian Fernández Domínguez is a lecturer and researcher with the Faculty of International Economics of the Autonomous University of Chihuahua (Mexico). Email: afernand@uach.mx.

Denise Gómez Hernández is a lecturer and researcher with the Faculty of Accounting and Administration of the Autonomous University of Querétaro (Mexico). Email: denise.gomez@uaq.mx. 


\section{Introduction}

The concept of multidimensional well-being has recently become more prominent, even though it has been implied in literature for some time. For example, Hicks (2002) and Nafziger (2005) cite a number of basic functionings related to well-being, such as adequate nutrition, the absence of premature mortality and the ability to appear in public without shame. The focus has largely been on material aspects of well-being; for instance, there have been vogues for certain objective measures such as the human development index ( $\mathrm{HDI}$ ) or reductions in the number of people living in poverty. Lately, however, there has been greater emphasis on the measurement of the intangible elements of multidimensional well-being (Bérenger and Verdier-Chouchane, 2007; Aiginger and Firgo, 2015; Arita, 2005), highlighting the importance of including a subjective well-being perspective in analysis.

Mexico's goal of increasing residents' living standards and well-being is clearly reflected in its 2013-2018 National Development Plan (Mexico, Government of, 2013). In this regard, OECD (2014) explains that in order to implement appropriate public policy, it is crucial that indicators properly reflect peoples' well-being. The issue therefore revolves around two questions: who is most well-off and why. As regards the second question, literature offers various conceptions and theories regarding what wellbeing is and what its determinants are, ranging from Greek philosophers' concepts of eudaemonia to the latest approaches built around capabilities and subjective well-being. The report prepared by Stiglitz, Sen and Fitoussi (2009) for the Commission on the Measurement of Economic Performance and Social Progress outlines a theoretical framework applicable to analysis of the multiple dimensions of well-being; these theoretical approaches are addressed in the second section of this article.

Turning back to the first question, Stiglitz, Sen and Fitoussi (2009) argue that the factors affecting a person's well-being require both objective and subjective data. They offer a number of recommendations, including development of a single summary measure of well-being, and suggest that consideration of well-being should address three theoretical approaches or conceptions that are prominent in literature: the theory of capabilities, the theory of subjective well-being and the theory of fair allocations. They also highlight indicators relating to various aspects or dimensions that affect well-being, such as disposable income, consumption and wealth (which relate to the dimension of material well-being), and others that relate to health, education, personal activities, political engagement, social connections, the environment and insecurity.

In their report, Stiglitz, Sen and Fitoussi (2009) also emphasize the importance of considering certain limiting factors when constructing a composite indicator of well-being: the loss of information on inequalities resulting from the use of averages, arbitrary weighting procedures, arbitrary selection of information on the relative contribution of each dimension of well-being, and interpretation of changes in the indicator over time. They also mention the advantages of analysing data at the individual level rather than at the state or regional level (since, for example, this allows inequality to be explored).

These elements have been inadequately applied to Mexico. Some endeavours have created indicators to measure well-being in Mexico; the most recent and noteworthy contribution, given its multidimensional approach, is that of the Organization for Economic Cooperation and Development (OECD) (2015), which is based on the well-being indicators by state (Indicadores de Bienestar por entidad federativa) (produced by Mexico's National Institute of Statistics and Geography (INEGI) and whose roots can be found in the OECD Better Life Index. However, this index has some limitations relating to the methodological elements mentioned by Stiglitz, Sen and Fitoussi (2009): it assumes that all dimensions are equally important in determining overall well-being, it does not capture the internal inequalities in each state ${ }^{1}$ and, although it uses subjective well-being data, they are not representative

\footnotetext{
1 Annex A1 shows that the construction of the index captures interstate inequality, but not necessarily inequality among a state's population. For example, in using mean disposable income per household, the same value may be seen in two states, even if disposable income is distributed differently.
} 
at state level. This study seeks to resolve these shortcomings by producing an indicator that: allows a different weight to be assigned to each dimension as recommended in the Handbook on Constructing Composite Indicators prepared by OECD (2008), ${ }^{2}$ attaches greater importance to inequality in line with Stiglitz, Sen and Fitoussi (2009), and uses data ${ }^{3}$ that is representative at state level.

This text is structured as follows: the second section deals briefly with the different conceptions and theories relating to well-being; the third section explains the methodology used to obtain the multidimensional well-being index, based on OECD (2008); the fourth section outlines the results obtained through this methodology and adapts other indicators to compare the differences that arise when considering different dimensions and indicators, as well as when allowing different weights; lastly, the fifth section provides some conclusions.

\section{Conceptions and theories of well-being}

The concept of well-being is complex and somewhat ambiguous. Any discussion of the topic must therefore begin with the various theories that have arisen since the Classical Greek concepts of eudaemonia and hedonism (Villatoro, 2012; Valencia and Cuervo, 1999). While the Greek philosophers' approach accepts that material goods are required to achieve well-being, special emphasis is placed on the contribution of the intangible (the psychological facet of man) to fullness of life or experiential pleasure. Classical philosophy's focus on human beings' quest for fullness links it with subjective well-being, as will be addressed later; Bentham (2000) went so far as to argue that the principle of classical utility entailed a subjection of the individual to pleasure and pain experienced (and, therefore, to happiness acquired) as a result of his or her actions. Criticism of this utilitarian approach's inability to assign values to the well-being of individuals or to make comparisons led welfarists to determine well-being on the basis of people's choices from a set of alternatives (revealed preference) and to assign a numerical value to social states through social well-being functions (Villatoro, 2012).

For its part, the utilitarian approach to well-being linked to opulence scrutinizes an individual's situation in relation to his or her access to goods and services; thus, the greater the access to goods and services -through higher income - the greater the well-being of the individual. Sen (1984) explains that this approach defines well-being too restrictively and, by limiting an individual's well-being to fulfilment of desires (that is to say the individual obtains well-being from consumerism), it overlooks important elements.

These approaches are criticized for not describing the origin of the desires that lead to decision-making, in other words for not specifying the intrinsic value of well-being. For example, Rawls (1971) asserts that significant well-being could be achieved (from a utilitarian point of view) by permitting organized crime to operate and generate proceeds, entailing increased economic movement and greater violence. Therefore, Rawls (1971) proposes well-being based on social justice: well-being achieved by obtaining primary goods catalogued as natural (such as food or clothing) or social (such as freedom, rights, opportunities, income and institutions related to justice). This approach postulates that well-being comes from more equitable distribution and proposes an in-depth analysis of a number of theories of justice, such as the theory of fair allocations.

Based on Kolm's (1997) criterion of equity in the absence of envy, the simplest efficient fair allocation is one in which all individuals are assigned the same set of goods; however, greater knowledge of the characteristics of the population and of available goods allows fair allocations to be made even

\footnotetext{
2 The handbook provides a number of analytical tools and recommendations for construction of composite indicators in 10 steps; for multivariate analysis and weighting, this study focuses on factor analysis of principal components and Cronbach's alpha (the technical aspects are addressed in annex A1).

3 Mexico's National Institute of Statistics and Geography (INEGI) mentions that politically, the country is organized into 32 states.
} 
if they vary from one individual to the next (Thomson, 2016). In other words, it is possible to allocate different goods to individuals in a society without them being worse off than they would have been if the same set of goods were allocated to everyone. In this respect, the theory of fair allocations allows neutral judgment, since each individual has a conception of the good, but it also has the shortcoming of assuming that the good will actually have the expected effect on each of the individuals (Wells, 2016).

As an alternative to these theories, the models regarding capabilities arose (Stiglitz, Sen and Fitoussi, 2009; Bérenger and Verdier-Chouchane, 2007), in which well-being is not achieved through the characteristics of the consumed good, as utility theory posits, or through the allocation and conception that the individual has of the good, as fair allocations theory proposes, but through the freedom that the person obtains from the capability to do or to be (Sen, 1984); that is to say, well-being comes from the functioning derived from the capability obtained from the good (Plata, 1999). According to Sen (1984), well-being is related to the individual's freedom to function in a certain way; hence, goods must provide the individual with the ability to choose the way to function (to be or do) and not just to do things (Beckley, 2002). In this regard, a set of basic functionings provide the individual with well-being, such as being adequately nourished, avoiding premature mortality, appearing in public without shame, being happy and being free (Hicks, 2002; Nafziger, 2005). According to this approach, well-being goes beyond what is established in utility theory, hence the creation of the human development index by the United Nations Development Programme (UNDP) (Bérenger and Verdier-Chouchane, 2007).

Another group of authors employ a more complex approach, subjective well-being theory, which argues that the well-being of the individual as a human being depends on one's own perception of different spheres or domains of life, influenced by both material (economic) and non-material aspects (Bonini, 2008; Rojas, 2005, 2007; Lever, 2004). Since well-being entails elements that cannot be quantified, such as emotional aspects, the proposal of this approach is to determine well-being through an indicator of life satisfaction or happiness obtained by asking the individual directly how satisfied or happy he or she is in life (Veenhoven, 2005).

Two important features of these theories stand out: well-being is multidimensional (it contains subjective and objective aspects), and the importance of each dimension in overall well-being is variable. Some authors (Villatoro, 2012; Krauss and Graham, 2013; Stiglitz, Sen and Fitoussi, 2009; Rojas, 2007), despite not rejecting the capabilities approach (or the objective aspect of well-being), stress the need to include the subjective sphere in well-being analyses, in spite of the difficulty this involves. Indeed, it would be beneficial to propose a measure of well-being that incorporates objective aspects (such as the levels of education, health and income considered in the capabilities approach) and subjective aspects (perception of satisfaction or happiness), in addition to examining the contribution of each of these aspects to the composition of individuals' overall well-being.

Some publications have addressed the multidimensional nature of well-being. For example, Bérenger and Verdier-Chouchane (2007), in an international study, partially address the multidimensional nature of well-being in 170 countries through factor analysis and fuzzy sets theory, but only analyse the contribution of the objective dimension of well-being (quality of life and standards of living). In another international study that examines Mexico, Benvin, Rivera and Tromben (2016) incorporate the resource of time as a dimension of well-being which, in addition to having a direct impact on well-being, is correlated with other dimensions; however, as in the study by Bérenger and Verdier-Chouchane (2007), their multidimensional approach to well-being only encompasses objective aspects.

In contrast, in a local study in Mexico, Arita (2005) performs a multidimensional analysis considering subjective and objective aspects of well-being at the individual level. Her study offers a preliminary examination of the multidimensional nature of well-being in Mexico, as proposed by Stiglitz, Sen and Fitoussi (2009): through factor analysis, it provides information on the percentage change in well-being explained by each dimension. However, its results cannot be extrapolated to the entire nation, since it only includes information on the well-being of the residents of the city of Culiacán, in the state of Sinaloa. 
Lastly, OECD (2015) offers a broader study, which also considers the multidimensional nature of well-being in Mexican states. The study is based on the framework of the OECD Better Life Index (which in turn stems from the recommendations of Stiglitz, Sen and Fitoussi, 2009) and on OECD and INEGI studies and databases on regional well-being. It provides recent information on twelve dimensions of well-being, as well as a global well-being index by state. However, the results cannot be considered entirely reliable if one takes into account the criticism and recommendations on creation of well-being indicators discussed above.

The OECD study (2015) presents a global well-being index by state, constructed from the mean and variance of Adjusted Mazziotta-Pareto Indices (AMPI) obtained for each dimension of well-being. All the indicators considered have the same importance, or weight, in the construction of the index. Each AMPI, in turn, is constructed from the mean and variance of normalized indicators, such as average disposable income. Therefore, by means of this methodology it is possible to obtain the same AMPI value 4 for a dimension in two states that have different distributions. In addition, the data used in relation to subjective well-being indicators were taken from a survey performed by INEGI that was not representative at state level. Based on the above, it can be argued, firstly, that the OECD study arbitrarily attaches equal importance to each dimension of well-being and, secondly, that it pays less attention to inequality within each state, which is relevant in a country such as Mexico.

\section{Methodology}

The multidimensional index of well-being at state level (IMBE) has been constructed based on the recommendations in the OECD Handbook on Constructing Composite Indicators (2008) and the report by Stiglitz, Sen and Fitoussi (2009). Based on the OECD guidelines (2008), equation (1) is established:

$$
I M B E_{i}=\sum W_{k}\left(\sum w_{j k} x_{i j}\right)
$$

where:

$I M B E_{i}$ is the multidimensional index of well-being of state $i$

$W_{k}$ is the ratio of variance in the principal component $k$ to total variance in the components considered in the construction

$x_{i j}$ is the value of each indicator $j$ for state $i$

$w_{j k}$ is the normalized weight for indicator $j$ and component $k$

In order to calculate $I M B E_{i}$, the values of $W_{k}$ and $w_{j k}$ must first be determined, as obtained from factor analysis of principal components. However, before this it is necessary to analyse whether the $x_{i j}$ indicators to be selected are related to each other, that is, whether they jointly explain the dimension of well-being to be determined. To this end, an exploratory (graphical) analysis of these indicators is performed to obtain a preliminary idea of the nature and magnitude of the relations between them. The limiting factors indicated by Stiglitz, Sen and Fitoussi (2009) are recognized using microdata at the individual level to obtain information concerning inequality, and the factor analysis technique is applied to allow for differences in the weighting factors for each dimension. In addition, measurable and representative state-level information on subjective well-being is used.

\footnotetext{
4 In a hypothetical example, a state whose inhabitants all have a value of 5 on a certain indicator will have the same state average as a state in which half the inhabitants have a value of 0 and the other half have 10 on the same indicator (in both cases a state average of 5 would be obtained).
} 
Consideration was given to constructing $I M B E_{i}$ based on the eight dimensions set down by Stiglitz, Sen and Fitoussi (2009). These authors suggest a broad list of indicators to consider in each dimension; however, owing to the relatively low number of observations (32 states) and the statistical restrictions of the methods used, the available indicators that were expected to contribute the most information on each dimension were incorporated into $x_{i j}$. The indicators used to construct $I M B E_{i}$, listed in table 1, are: median total current income (income and wealth) (inghmed), disposable income adjusted for the state Gini coefficient (ingaj), median total annual household spending adjusted by consumption unit (gpcmed), mean reported health status (situsalud), mean access to health (accesalud), mean accumulated schooling (educ), mean satisfaction with activity performed (satisactiv), mean reported freedom of choice (libertad), mean satisfaction with social life (satissocial), air pollution ( $\left.\mathrm{CO}_{2}\right)$, and mean satisfaction with public safety (satissecure).

Table 1

Dimensions and indicators considered in each well-being index

\begin{tabular}{|c|c|c|c|c|c|}
\hline \multicolumn{2}{|c|}{$\begin{array}{c}\text { Multidimensional index of } \\
\text { well-being at state level (IMBE) }\end{array}$} & \multicolumn{2}{|c|}{$\begin{array}{l}\text { BLI well-being index, based on } \\
\text { the OECD Better Life Index }\end{array}$} & \multicolumn{2}{|c|}{$\begin{array}{l}\text { SoL well-being index, based on } \\
\text { Bérenger and Verdier-Chouchane }{ }^{c}\end{array}$} \\
\hline Dimensions & Indicators & Dimensions & Indicators & Dimensions & Indicators \\
\hline \multirow[t]{3}{*}{$\begin{array}{l}\text { Material living } \\
\text { standards (income, } \\
\text { consumption, wealth) }\end{array}$} & $\begin{array}{l}\text { Median total } \\
\text { current income* }\end{array}$ & Housing & $\begin{array}{l}\text { Rooms per person*; Dwellings with } \\
\text { roofs made of resistant materials* }\end{array}$ & $\begin{array}{l}\text { Material } \\
\text { well-being }\end{array}$ & $\begin{array}{l}\text { Gini coefficient of } \\
\text { household disposable } \\
\text { income per capita* }\end{array}$ \\
\hline & $\begin{array}{l}\text { Disposable income } \\
\text { adjusted for } \\
\text { Gini coefficient* }\end{array}$ & Income & $\begin{array}{l}\text { Gini coefficient of disposable } \\
\text { income*; Equivalized disposable } \\
\text { income*; population living } \\
\text { in poverty*; population living } \\
\text { in extreme poverty* }\end{array}$ & & $\begin{array}{l}\text { Median current household } \\
\text { income per capita* }\end{array}$ \\
\hline & $\begin{array}{l}\text { Median total } \\
\text { annual household } \\
\text { spending adjusted for } \\
\text { consumption units* }\end{array}$ & Employment & $\begin{array}{l}\text { Critical employment } \\
\text { conditions }^{\star} \text {; labour informality*; } \\
\text { unemployment*; employment* }\end{array}$ & & $\begin{array}{l}\text { Household disposable } \\
\text { income per capita* }\end{array}$ \\
\hline \multirow[t]{2}{*}{ Health } & Health status ${ }^{\star \star}$ & $\begin{array}{l}\text { Access to } \\
\text { services }\end{array}$ & $\begin{array}{l}\text { Access to health services*; } \\
\text { households with broadband } \\
\text { access*; dwellings with access } \\
\text { to basic services* }\end{array}$ & & $\begin{array}{l}\text { Total annual household } \\
\text { spending adjusted for } \\
\text { consumption units* }\end{array}$ \\
\hline & Access to health* & $\begin{array}{l}\text { Safety and } \\
\text { security }\end{array}$ & $\begin{array}{l}\text { Homicide*; }^{*} \text { confidence in police } \\
\text { perception of insecurity } \\
\text { crime rate }^{\star *}\end{array}$ & & $\begin{array}{l}\text { Current household } \\
\text { income adjusted for } \\
\text { the Gini coefficient* }\end{array}$ \\
\hline Education & $\begin{array}{l}\text { Accumulated } \\
\text { schooling }^{*}\end{array}$ & Education & $\begin{array}{l}\text { Levels of education*; school dropout } \\
\text { rate*; Programme for International }^{\star} \text { Student Assessment (PISA) Test* }^{\star}\end{array}$ & Education & Accumulated schooling* \\
\hline $\begin{array}{l}\text { Personal activities, } \\
\text { including work }\end{array}$ & $\begin{array}{l}\text { Satisfaction with } \\
\text { activity performed }\end{array}$ & Environment & Air pollution*; waste disposal* & & \\
\hline $\begin{array}{l}\text { Political voice } \\
\text { and governance }\end{array}$ & Freedom of choice ${ }^{\star \star}$ & $\begin{array}{l}\text { Civic } \\
\text { engagement } \\
\text { and } \\
\text { governance }\end{array}$ & $\begin{array}{l}\text { Civic and political engagement*; } \\
\text { voter turnoutt; confidence in } \\
\text { application of law }{ }^{\star *} ; \text { perception } \\
\text { of absence of corruption }\end{array}$ & Health & Current health status ${ }^{\star *}$ \\
\hline $\begin{array}{l}\text { Social connections } \\
\text { and relationships }\end{array}$ & $\begin{array}{l}\text { Satisfaction with } \\
\text { social life }^{\star \star}\end{array}$ & Health & $\begin{array}{l}\text { Life expectancy at birth*; } \\
\text { self-reported health**; obesity*; } \\
\text { maternal mortality*; infant mortality* }\end{array}$ & & $\begin{array}{l}\text { Satisfaction with } \\
\text { current health** }\end{array}$ \\
\hline $\begin{array}{l}\text { Environment } \\
\text { (present and future) }\end{array}$ & Air pollution* & $\begin{array}{l}\text { Work-life } \\
\text { balance }\end{array}$ & $\begin{array}{l}\text { Satisfaction with leisure time**; } \\
\text { employees who work long hours* }\end{array}$ & & Access to health* \\
\hline \multirow[t]{2}{*}{$\begin{array}{l}\text { Insecurity (economic } \\
\text { and physical) }\end{array}$} & $\begin{array}{l}\text { Satisfaction with } \\
\text { public safety }{ }^{\star \star}\end{array}$ & $\begin{array}{l}\text { Community } \\
\text { (social } \\
\text { connections) }\end{array}$ & Social support network ${ }^{\star \star}$ & $\begin{array}{l}\text { Subjective } \\
\text { well-being }\end{array}$ & $\begin{array}{l}\text { Self-reported life } \\
\text { satisfaction-well-being }^{\star *}\end{array}$ \\
\hline & & $\begin{array}{l}\text { Life } \\
\text { satisfaction }\end{array}$ & Life satisfaction ${ }^{\star \star}$ & & \\
\hline
\end{tabular}

Source: Prepared by the authors, on the basis of Stiglitz, J., A. Sen and J. Fitoussi (2009), Report by the Commission on the Measurement of Economic Performance and Social Progress, Paris, The Commission, and Bérenger, V. and A. Verdier-Chouchane (2007), "Multidimensional measures of well-being: standard of living and quality of life across countries", World Development, vol. 35, No. 7, Amsterdam, Elsevier.

Note: * Objective well-being indicator; ${ }^{*}$ subjective well-being indicator.

a Based on Stiglitz, Sen and Fitoussi (2009).

b Organization for Economic Cooperation and Development (OECD), 2015.

c Bérenger and Verdier-Chouchane, 2007. 
According to OECD (2008), factor analysis of principal components enables formation of a composite indicator that captures as much as possible of the information common to a group of variables, so that the composite indicator does not depend on the dimensionality of the data. For this reason, after graphical analysis of the $x_{i j}$ indicators, the second step is to calculate the Cronbach coefficient alpha, which makes it possible to measure the reliability (a preliminary idea of contribution) of each indicator in the global well-being index and, in this way, to select the $x_{i j}$ indicators that actually contribute significantly to $I M B E_{i}$ and that maintain the principle of parsimony. As a third step, correlations between the $x_{i j}$ indicators are analysed, observing the multidimensionality of $I M B E_{i}$. Subsequently, in the fourth step a factor analysis of principal components is performed (some technical notes regarding these steps are included in annex A1).

Lastly, in the fifth step, $I M B E_{i}$ is compared with other well-being indicators. This comparison can be seen in table 1: in the first column the dimensions and indicators included in the proposed $I M B E_{i}$ index are marked in bold, while the second and third columns show the dimensions and indicators of two additional indices, obtained using the same methodology of factor analysis of principal components, but adapted, respectively, from the multidimensional approach of the OECD Better Life Index (2015) $\left(B L I_{i}\right)$ and from the approach detailed by Bérenger and Verdier-Chouchane (2007) (SoL $)$.

\section{Data}

Given the availability of information at the microdata or state levels, there are two means of obtaining representative data for each state: (i) indicators based on information obtained directly from the state, which are not transformed and are used directly, and; (ii) indicators obtained from information at the individual level from surveyed households, transformed from state medians or means - as the case may be- weighted according to the adjustment (expansion) factor provided by INEGI. This expansion factor indicates how the national agency segments the total population by strata and primary sampling units, thus allowing estimates to be made from representative samples.

The data used in the analysis are from INEGI and OECD. Specifically, the inghmed, educ and accesalud indicators have been calculated from the Socioeconomic Conditions Module of the 2014 National Household Income and Expenditure Survey (ENIGH); the situsalud, satisactiv, libertad, satissocial and satissecure indicators, from the Self-Reported Well-Being Module (BIARE) 2014; the ingaj indicator, from 2014 OECD disposable income data and the INEGI Better Life Index project (Gini coefficient data); the gpcmed indicator has been calculated from the 2013 National Household Expenditure Survey (ENGASTO); and the $\mathrm{CO}_{2}$ air pollution indicator from the INEGI Better Life Index project.

INEGI provides key variables that allow the information from the databases of the Socioeconomic Conditions Module and the Self-Reported Well-Being Module for the same person or household to be combined, in such a way that objective and subjective information on well-being can be analysed together. In addition, although the National Household Income and Expenditure Survey has been available since 1984, representative state-level Self-Reported Well-Being Module data have only been available since 2014 . The other state data used to construct the $B L I_{i}$ index can be found in the INEGI Better Life Index project. The following section shows the results of the described analysis, performed using the Stata 13 software package.

\section{Results}

\section{Analysis of indicators}

Once the indicators whose data were obtained at the individual level are transformed, graphical analysis of the relationships between them provides interesting insight. Figure 1 shows that, in general, there is a well-defined positive relationship between the first six indicators (median total current income, disposable 
income adjusted for the Gini coefficient, median consumer spending, health access, health status, and schooling). The indicators of income, health and education, corresponding to the six indicators mentioned above, make up the human development index. All the indicators, except current health status and including air pollution, relate to objective well-being. The rest of the indicators, which relate to subjective well-being, do not generally show a clearly defined relationship with other indicators, especially those of objective well-being. This may be because the subjective well-being indicators used deal with aspects of life that have little relation to labour or material matters.

Figure 1

Relationship between well-being indicators

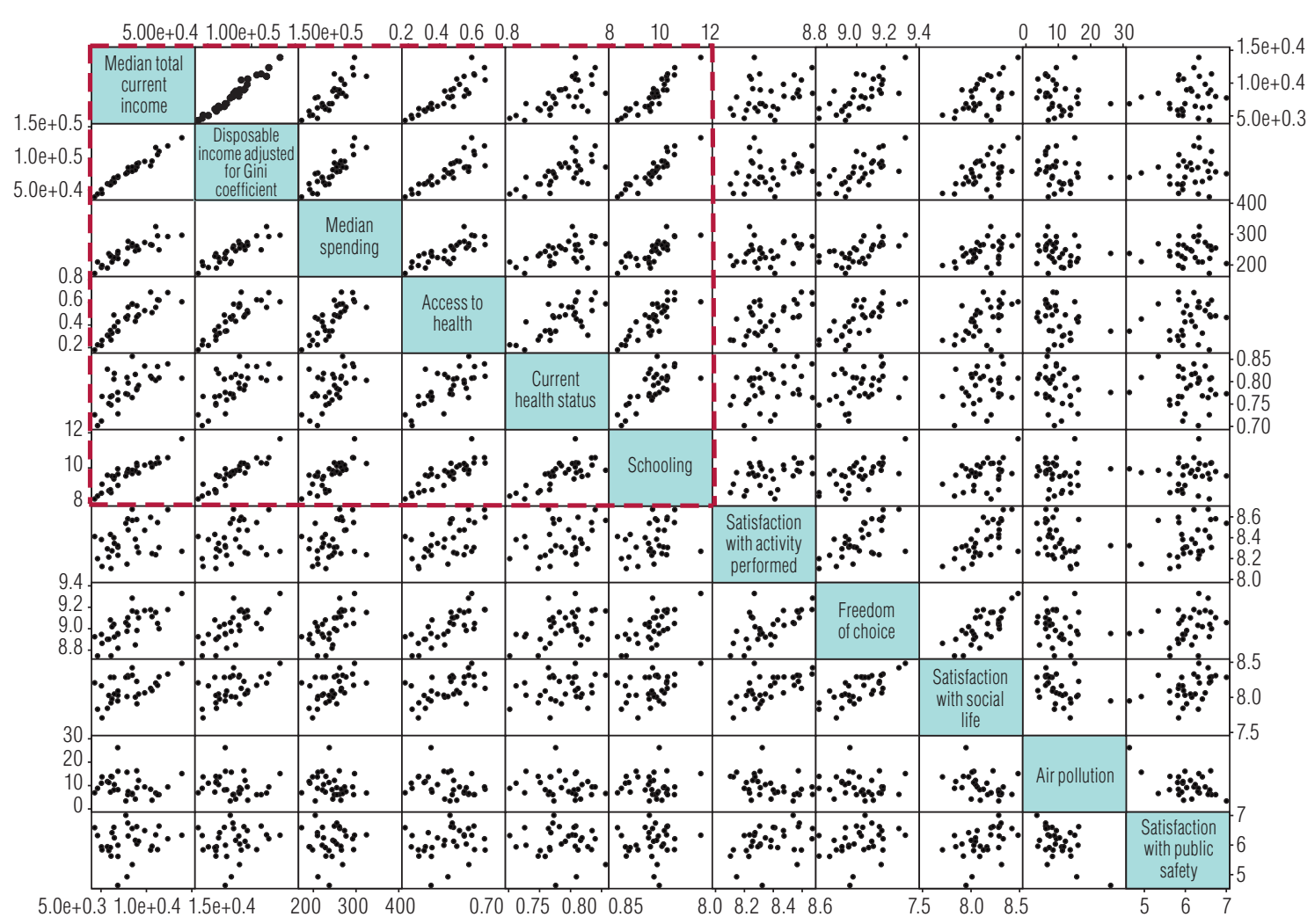

Source: Prepared by the authors, on the basis of official data from the National Institute of Statistics and Geography (INEGI) and the Organization for Economic Cooperation and Development (OECD).

\section{Cronbach coefficient alpha}

In the second stage, a reliability test is performed using Cronbach's alpha to verify that the chosen indicators $x_{i j}$ provide information at the scale of the underlying variable "well-being" (or $I M B E_{i}$ ). The Cronbach coefficient alpha is calculated with standardized data, since the indicators are in different units. Table 2 shows that average correlation between the $11 x_{i j}$ indicators is 0.4855 , which is not very high, but Cronbach's alpha is 0.9121 . Although this value is relatively high, it is important to carry out contribution tests to verify that the indicators used contribute significantly and in the expected direction to the scale; it is also important to verify that the value obtained is not compromised by a failure to comply with the test assumptions. 
Table 2

Cronbach's alpha

\begin{tabular}{lc}
\hline Average inter-item correlation: & 0.4855 \\
\hline Number of items in the scale: & 11 \\
\hline Scale reliability coefficient: & 0.9121 \\
\hline
\end{tabular}

Source: Prepared by the authors, on the basis of data from the National Institute of Statistics and Geography (INEGI).

Table 3 shows information regarding the contribution and correlation of each indicator in the scale calculated using Cronbach's alpha. The "Remarks" column indicates that for calculation of Cronbach's alpha, information was obtained for each indicator from all 32 states of the country, meaning that no data was lost or omitted. The "Sign" column indicates the direction of each indicator on the scale built using Cronbach's alpha, that is to say how each of them contributes to the well-being scale: a positive sign indicates that a higher value of the corresponding indicator relates to a higher value on the scale. As previously mentioned, the indicators have the sign that is expected in theory: greater well-being is reflected in higher median total current household income, more disposable income adjusted for the Gini coefficient, higher median consumer spending, greater accumulated schooling, greater access to health, better health status, greater satisfaction with the activity performed, greater freedom of choice, greater satisfaction with social life, less air pollution and greater satisfaction with public safety.

Table 3

Details of Cronbach's alpha correlation

\begin{tabular}{lcccccc}
\hline \multicolumn{1}{c}{ Indicator } & Remarks & Sign & ITC $^{\text {a }}$ & IRC $^{b}$ & IC C $^{\text {C }}$ & C-a cont $^{\text {d }}$ \\
\hline Median current household income per capita & 32 & + & 0.8870 & 0.8554 & 0.4574 & 0.8940 \\
\hline Current household income adjusted for the Gini coefficient & 32 & + & 0.8867 & 0.8550 & 0.4575 & 0.8940 \\
\hline Median adjusted total annual expenditure per person & 32 & + & 0.8125 & 0.7629 & 0.4707 & 0.8989 \\
\hline Access to health & 32 & + & 0.9207 & 0.8979 & 0.4514 & 0.8916 \\
\hline Current health status & 32 & + & 0.6801 & 0.6040 & 0.4943 & 0.9072 \\
\hline Schooling & 32 & + & 0.8230 & 0.7758 & 0.4688 & 0.8982 \\
\hline Satisfaction with activity performed & 32 & + & 0.6354 & 0.5517 & 0.5023 & 0.9098 \\
\hline Freedom of choice & 32 & + & 0.8367 & 0.7927 & 0.4664 & 0.8973 \\
\hline Satisfaction with social life & 32 & + & 0.7361 & 0.6704 & 0.4843 & 0.9038 \\
\hline Air pollution & 32 & - & 0.4234 & 0.3132 & 0.5401 & 0.9215 \\
\hline Satisfaction with public safety & 32 & + & 0.3835 & 0.2699 & 0.5472 & 0.9236 \\
\hline Scale & & & & & 0.4855 & 0.9121 \\
\hline Source: Prepar
\end{tabular}

Source: Prepared by the authors, on the basis of official data from the National Institute of Statistics and Geography (INEGI) and the Organization for Economic Cooperation and Development (OECD).

a Indicator-scale correlation.

b Indicator-rest correlation.

c Average inter-item correlation.

d Contribution to Cronbach's alpha if indicator omitted.

The correlation of each indicator with the scale obtained through Cronbach's alpha of the 11 included indicators is indicated in the "ITC" column of table 3; in this case, the least correlated are satisfaction with public safety and air pollution. Since the inclusion of these indicators influences the scale obtained, it is useful to draw on the information in the "IRC" column (StataCorp, 2013), which indicates the correlation of each indicator with the scale obtained from the other 10; in this case the correlation of satisfaction with public safety and air pollution is even lower, suggesting that these indicators are not well adapted to the overall scale obtained. 
The "IIC" column in table 3 shows average correlations between the indicators, except for that appearing in the row in question; in this case, as previously mentioned, average correlation between the indicators is 0.4855 , but if the satisfaction with public safety indicator or the air pollution indicator are omitted, average correlation increases to 0.5472 or 0.5401 , respectively. Lastly, the "C-a cont" column provides information on the change in Cronbach's alpha when an indicator is omitted; again, the omission of one of the two aforementioned indicators improves the scale obtained, since the alpha increases to 0.9236 or 0.9215 , respectively.

An important aspect of these results is that, although the Cronbach's alpha obtained is relatively high, the number of observations considered in the calculation is relatively low. Therefore, according to relevant literature, the reliability of the statistical analysis may be compromised. Specifically, Yurdugül (2008) argues that the reliability of the test depends not only on the number of observations, but also on the eigenvalue obtained through principal component analysis; according to Yurdugül's Monte Carlo studies, a sample of 30 observations is reliable if the eigenvalue of the first component obtained through principal component analysis is higher than 6.00. If the test is performed using the data from this study, the eigenvalue of the first component is higher than six (see table 5), so it can be argued that the Cronbach coefficient alpha obtained is reliable.

The results obtained thus far present some items for discussion, and enable the study to proceed with confidence to factor analysis: although the indicators of satisfaction with public safety and air pollution do not provide a large amount of information on the scale obtained using the coefficient alpha, their omission does not increase the reliability of the scale significantly; similarly, the indicators of material living standards, education and health may be providing duplicated information. Nonetheless, none of these indicators $x_{i j}$, which are important in the theory of Stiglitz, Sen and Fitoussi (2009), compromise the validity of the statistical analysis, and they all provide information regarding the multiple dimensions of well-being. For these reasons, they have not been omitted from the subsequent analysis.

\section{Principal components analysis}

As mentioned above, OECD (2008) stresses the need for correlation among the indicators of interest $x_{i j}$; without this, there would be no sense in performing a factor analysis of principal components. With regard to the third stage of the analysis, the correlation matrix in table 4 confirms the existence of two main groups of indicators: on the one hand, material standards of living and indicators of the education and health dimensions are highly and significantly correlated, with low or non-significant correlation with the other indicators; on the other hand, there are significant (although not as marked) correlations between the remaining indicators, related to individuals' satisfaction, supporting the decision not to omit them from the analysis. Another important aspect is that the signs of the correlations are as expected, according to theory and to what was discussed in the Cronbach's alpha analysis. Thus, the set of indicators $x_{i j}$ behaves as desired and is not expected to present problems in the factor analysis.

With regard to the fourth stage, table 5 shows the factor analysis of principal components of the selected indicators $x_{i j}$. The top portion of the results shows that information from the 11 indicators for the 32 states considered was used for the calculation. It is clear that, in accordance with the criteria presented in the methodology, only the first two factors should be used to construct the well-being index shown in equation (1), since they are the only ones that have an eigenvalue of more than 1 (column 2) and explain more than $60 \%$ of the total variance (columns 4 and 5). In order to confirm the existence of correlation between the indicators used, a test of independence among the indicators is performed; in other words, the null hypothesis is that the elements below the diagonal of the variance-covariance matrix have a value of 0 , and it is rejected at $95 \%$, as shown at the bottom of the table. 
Table 4

Matrix of correlations between state-level well-being indicators

\begin{tabular}{|c|c|c|c|c|c|c|c|c|c|c|}
\hline & inghmed & ingaj & gpcmed & accesalud & situsalud & educ & satisactiv & libertad & satissocial & $\mathrm{CO}_{2}$ \\
\hline inghmed & 1 & & & & & & & & & \\
\hline ingaj & $0.9806^{*}$ & 1 & & & & & & & & \\
\hline gpcmed & $0.8467^{*}$ & $0.8709^{*}$ & 1 & & & & & & & \\
\hline accesalud & $0.8819^{*}$ & $0.8718^{*}$ & $0.8000^{*}$ & 1 & & & & & & \\
\hline situsalud & $0.6512^{*}$ & $0.6549^{*}$ & $0.5576^{*}$ & $0.7082^{*}$ & 1 & & & & & \\
\hline educ & $0.9091^{*}$ & $0.9103^{*}$ & $0.7684^{*}$ & $0.8274^{*}$ & $0.7321^{*}$ & 1 & & & & \\
\hline satisactiv & 0.3163 & 0.2969 & 0.3348 & $0.5404^{*}$ & 0.3204 & 0.3107 & 1 & & & \\
\hline libertad & $0.7030^{*}$ & $0.6991^{*}$ & $0.6328^{*}$ & $0.7464^{*}$ & $0.4850^{*}$ & $0.6753^{*}$ & $0.6096^{*}$ & 1 & & \\
\hline satissocial & $0.5085^{\star}$ & $0.5371^{*}$ & $0.4715^{\star}$ & $0.5633^{*}$ & 0.2431 & $0.4146^{*}$ & $0.6493^{*}$ & $0.7337^{*}$ & 1 & \\
\hline $\mathrm{CO}_{2}$ & -0.1810 & -0.1440 & -0.1839 & -0.2881 & -0.1874 & 0 & $-0.3584^{*}$ & -0.1461 & $-0.3723^{*}$ & 1 \\
\hline satissecure & 0.1402 & 0.1502 & 0.0542 & 0.1610 & -0.0818 & 0.0571 & $0.3623^{*}$ & 0.2837 & $0.4142^{*}$ & $-0.5363^{*}$ \\
\hline
\end{tabular}

Source: Prepared by the authors, on the basis of official data from the National Institute of Statistics and Geography (INEGI) and the Organization for Economic Cooperation and Development (OECD).

Note: The indicators are: median total current income (inghmed); disposable income adjusted for state Gini coefficient (ingaj); median total annual household spending adjusted for consumption units (gpcmed); mean access to health (accesalud); mean reported health status (situsalud); mean accumulated schooling (educ); mean satisfaction with activity performed (satisactiv); mean reported freedom of choice (libertad); mean satisfaction with social life (satissocial); air pollution $\left(\mathrm{CO}_{2}\right)$, and mean satisfaction with public safety (satissecure).

* Significant at $95 \%$.

Table 5

Principal components analysis

\begin{tabular}{lcccc}
\hline Factor analysis/correlation & \multicolumn{3}{l}{ Number of observations = 32 } \\
\hline $\begin{array}{l}\text { Method: principal component factors } \\
\text { Rotation: (unrotated) }\end{array}$ & \multicolumn{3}{c}{ Retained factors = } \\
\hline Factor & Eigenvalue & Difference & Proportion & Cumulative \\
\hline Factor1 & $\mathbf{6 . 3 1 4 6 4}$ & $\mathbf{4 . 3 8 8 3}$ & $\mathbf{0 . 5 7 4 1}$ & $\mathbf{0 . 5 7 4 1}$ \\
\hline Factor2 & $\mathbf{1 . 9 2 6 3 4}$ & $\mathbf{1 . 0 7 4 8 5}$ & $\mathbf{0 . 1 7 5 1}$ & $\mathbf{0 . 7 4 9 2}$ \\
\hline Factor3 & 0.85149 & 0.16178 & 0.0774 & 0.8266 \\
\hline Factor4 & 0.6897 & 0.25333 & 0.0627 & 0.8893 \\
\hline Factor5 & 0.43638 & 0.14494 & 0.0397 & 0.929 \\
\hline Factor6 & 0.29143 & 0.10878 & 0.0265 & 0.9555 \\
\hline Factor7 & 0.18265 & 0.03209 & 0.0166 & 0.9721 \\
\hline Factor8 & 0.15056 & 0.0605 & 0.0137 & 0.9939 \\
\hline Factor9 & 0.09006 & 0.03367 & 0.0082 & 0.9991 \\
\hline Factor10 & 0.05639 & 0.04603 & 0.0051 & 1.0000
\end{tabular}

Source: Prepared by the authors, on the basis of official data from the National Institute of Statistics and Geography (INEGI) and the Organization for Economic Cooperation and Development (OECD).

As mentioned in the previous section, the factors are rotated using the orthogonal varimax method, to subsequently obtain the normalized weightings or squared factor loadings $w_{j k}$. The results of the rotation are shown in table 6 . The upper portion of the table is similar to that of table 5 , except that it is now indicated that the factors were rotated using the orthogonal varimax method. The second part of the table shows the variance of each factor (eigenvalue) and its ratio to the variance of both ( $W k$ in equation (1)); the first factor is clearly the one with the highest weight (almost 70\%). The third section of the table has several columns: the second and third columns show the loadings for the two factors already transformed through rotation. As shown, the magnitudes of the loadings separate the indicators in each factor according to what was discerned in the correlation matrix and the scatter diagrams: the indicators of material living standards, health and education have greater loadings in the first factor, and the rest of the indicators (except freedom of choice) have greater loadings in the second factor. The 
"Uniqueness" column indicates that these factors are not omitting a considerable part of the variance of any indicator; according to StataCorp (2013), a value of more than 0.6 is considered high. In this regard, the air pollution indicator is the one that loses the most information (around $46 \%$ of its variance) in the analysis and subsequent construction of the index.

Table 6

Varimax rotation and generation of weighting factors

\begin{tabular}{|c|c|c|c|c|c|c|c|}
\hline \multicolumn{5}{|c|}{ Factor analysis/correlation } & \multicolumn{3}{|c|}{ Number of observations $=32$} \\
\hline \multicolumn{5}{|c|}{ Method: principal component factors } & \multicolumn{3}{|c|}{ Retained factors $=2$} \\
\hline \multicolumn{5}{|c|}{ Rotation: orthogonal varimax (Kaiser off) } & \multicolumn{3}{|c|}{ Number of parameters $=21$} \\
\hline Factor & \multicolumn{2}{|c|}{ Variance } & \multicolumn{2}{|c|}{ Proportion } & & & \\
\hline Factor1 & \multicolumn{2}{|c|}{5.72645} & \multicolumn{2}{|c|}{0.6948} & & & \\
\hline Factor2 & \multicolumn{2}{|c|}{2.51452} & \multicolumn{2}{|c|}{0.3052} & & & \\
\hline \multicolumn{8}{|c|}{ Rotated factor loadings (pattern matrix) and unique variances } \\
\hline Variable & FL1 & FL2 & Uniqueness & FL1sq & FL2sq & FL1norm & FL2norm \\
\hline inghmed & 0.9464 & 0.1399 & 0.0848 & 0.8956 & 0.0195 & 0.1564 & 0.0077 \\
\hline ingaj & 0.952 & 0.1307 & 0.0766 & 0.9063 & 0.0170 & 0.1582 & 0.0067 \\
\hline gpcmed & 0.8715 & 0.1237 & 0.2253 & 0.7595 & 0.0153 & 0.1326 & 0.0060 \\
\hline accesalud & 0.8987 & 0.2901 & 0.1081 & 0.8076 & 0.0841 & 0.1410 & 0.0334 \\
\hline situsalud & 0.7736 & -0.0114 & 0.4014 & 0.5984 & 0.0001 & 0.1045 & - \\
\hline educ & 0.948 & 0.0076 & 0.1013 & 0.8987 & - & 0.1569 & - \\
\hline satisactiv & 0.3372 & 0.7001 & 0.3962 & 0.1137 & 0.4901 & 0.0198 & 0.1949 \\
\hline libertad & 0.7275 & 0.4459 & 0.2719 & 0.5292 & 0.1988 & 0.0924 & 0.0790 \\
\hline satissocial & 0.4628 & 0.7016 & 0.2935 & 0.2141 & 0.4922 & 0.0374 & 0.1957 \\
\hline $\mathrm{CO}_{2}$ & -0.0314 & -0.735 & 0.4587 & 0.0009 & 0.5402 & 0.0001 & 0.2148 \\
\hline satissecure & -0.0457 & 0.8104 & 0.3412 & 0.0020 & 0.6567 & 0.0003 & 0.2611 \\
\hline
\end{tabular}

Source: Prepared by the authors, on the basis of official data from the National Institute of Statistics and Geography (INEGI) and the Organization for Economic Cooperation and Development (OECD).

Note: $\quad F L^{*}$ : factor loading 1 or 2; uniqueness: percentage of variance not explained by factors; FL*sq: squared loading; FL*norm: squared loading normalized by factor variance.

The indicators are: median total current income (inghmed); disposable income adjusted for state Gini coefficient (ingaj); median total annual household spending adjusted for consumption units (gpcmed); mean access to health (accesalud); mean reported health status (situsalud); mean accumulated schooling (educ); mean satisfaction with activity performed (satisactiv); mean reported freedom of choice (libertad); mean satisfaction with social life (satissocial); air pollution $\left(\mathrm{CO}_{2}\right)$, and mean satisfaction with public safety (satissecure).

The fifth and sixth columns of table 6 show the squared loadings, and the last two columns show the normalized loadings, which will serve as weighting factors in the construction of the $I M B E_{i}$ presented in equation (1). As indicated by OECD (2008), it is evident that varimax rotation enables weights to be obtained for each $x_{i j}$ indicator that are significant in a single factor; these weighting factors $\left(w_{j k}\right.$ in equation (1)) are shown in bold, meaning that the indicators relating to material standards of living, education, health and freedom of choice must be included in the first factor and the rest of the indicators in the second.

Before constructing the well-being index, as mentioned in the section on methodology, the Kaiser-Meyer-Olkin (KMO) measure of the communality of the indicators is calculated, to support the validity of a factor analysis. According to the scale provided by Kaiser (1974), cited in StataCorp (2013), values between 0.80 and 0.89 are "meritorious" and values between 0.70 and 0.79 are "middling" but acceptable (OECD, 2008). The results presented in table 7 indicate that the measure of the factor used is acceptable, even though the last two indicators have a rather low value. 
Table 7

Kaiser-Meyer-Olkin measure

\begin{tabular}{lc}
\hline Indicator & Kaiser-Meyer-Olkin measure (KM0) \\
\hline inghmed & 0.7370 \\
\hline ingaj & 0.6843 \\
\hline gpcmed & 0.7913 \\
\hline accesalud & 0.919 \\
\hline situsalud & 0.6634 \\
\hline educ & 0.8887 \\
\hline satisactiv & 0.6785 \\
\hline libertad & 0.8087 \\
\hline satissocial & 0.6356 \\
\hline CO & 0.2909 \\
\hline satissecure & 0.3355 \\
\hline Total & 0.7139 \\
\hline
\end{tabular}

Source: Prepared by the authors.

Note: The indicators are: median total current income (inghmed); disposable income adjusted for state Gini coefficient (ingaj); median total annual household spending adjusted for consumption units (gpcmed); mean access to health (accesalud); mean reported health status (situsalud); mean accumulated schooling (educ); mean satisfaction with activity performed (satisactiv); mean reported freedom of choice (libertad); mean satisfaction with social life (satissocial); air pollution $\left(\mathrm{CO}_{2}\right)$, and mean satisfaction with public safety (satissecure).

Finally, the well-being index for the 32 states is constructed on the basis of equation (1) and the $W_{k}$ and $w_{j k}$ weighting factors from table 6. According to Aiginger and Firgo (2015), the index score is Min-Max normalized so that the state with the highest well-being score has 1 and the state with the lowest score has 0 . The $I M B E_{i}$ of the states of Mexico is presented in figure 2, with the normalized value of $I M B E_{i}$ on the $y$ scale and the 32 states ordered on the $x$ scale from highest to the lowest level of well-being.

Figure 2

Mexico: multidimensional index of well-being at state level (IMBE), 2014 (Normalized values between 0 and 1)

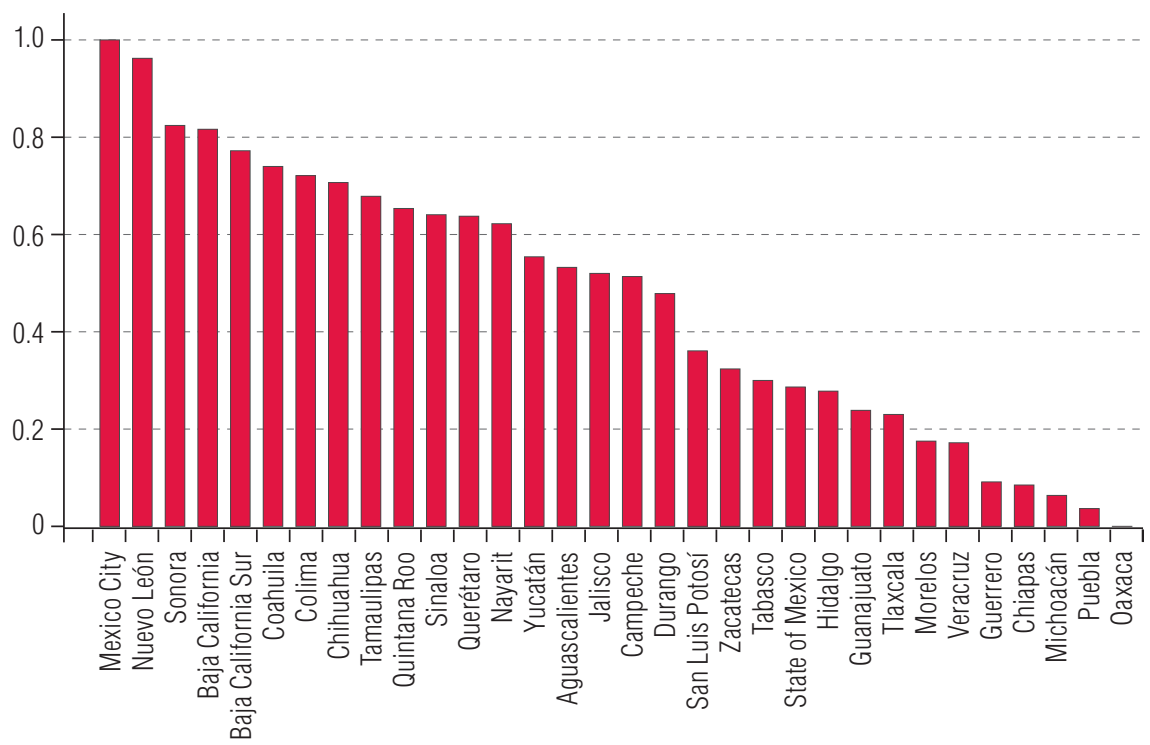

Source: Prepared by the authors, on the basis of official data from the National Institute of Statistics and Geography (INEGI) and the Organization for Economic Cooperation and Development (OECD). 
Overall, it is shown that $I M B E_{i}$ reflects the relatively high weights assigned to the indicators of material living standards in the first component obtained through the principal component analysis and therefore also relatively high weights in the index. The states with the greatest well-being are Mexico City and Nuevo León, while the states with the lowest well-being are Puebla and Oaxaca. In addition, the well-being gaps divide the federative states into three groups: firstly, federative states with low well-being (less than 0.4), encompassing Oaxaca to San Luis Potosí; secondly, states with medium well-being (0.4 to 0.6), covering Durango to Yucatán, and; lastly, states with high well-being (more than 0.6), comprising Nayarit to Mexico City.

As the fifth stage of the aforementioned analysis, it is interesting to examine whether these results tally with the information provided by other indicators of well-being. To this end, a comparison is first made with the constructed indicators (the human development index and overall life satisfaction indicator) and then with the $S_{S} L_{i}$ and $B L I_{i}$ indices. Figure 3 compares the $I M B E_{i}$ results with the 2012 state HDI (the most recent HDI provided by the United Nations Development Programme in Mexico), which groups income, education and health information, and also with the life satisfaction indicator provided by the 2014 Self-Reported Well-Being Module (BIARE).

Figure 3

Mexico: relationship of the multidimensional index of well-being at state level (IMBE) with the 2012 human development index (HDI) and with the life satisfaction indicator of the 2014 Self-Reported Well-being Module (BIARE)

A. Relationship with the HDI

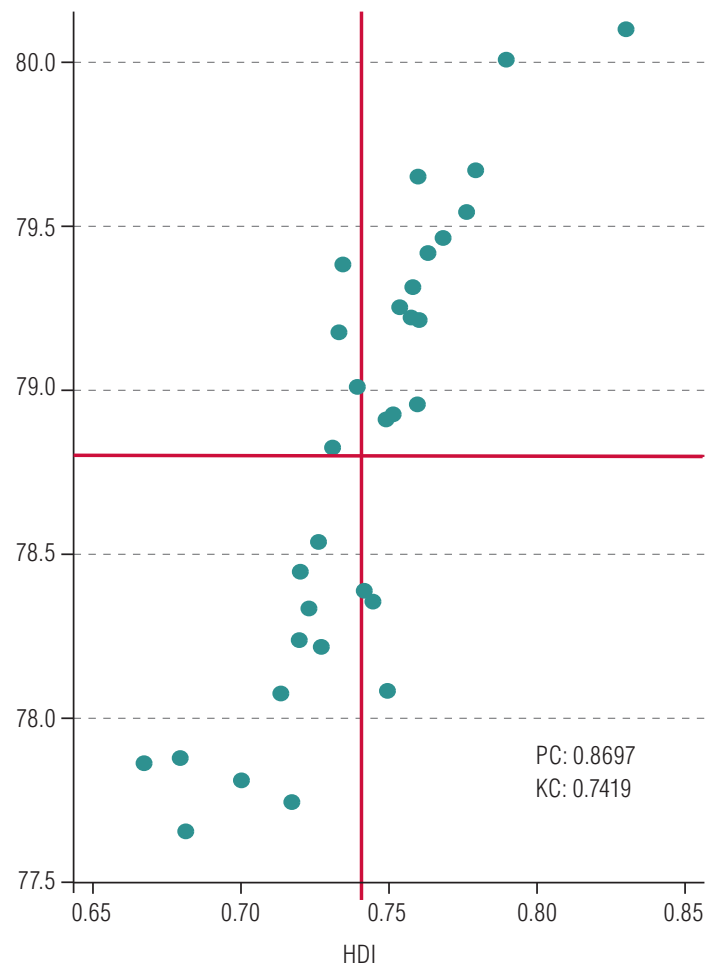

B. Relationship with the BIARE life satisfaction indicator

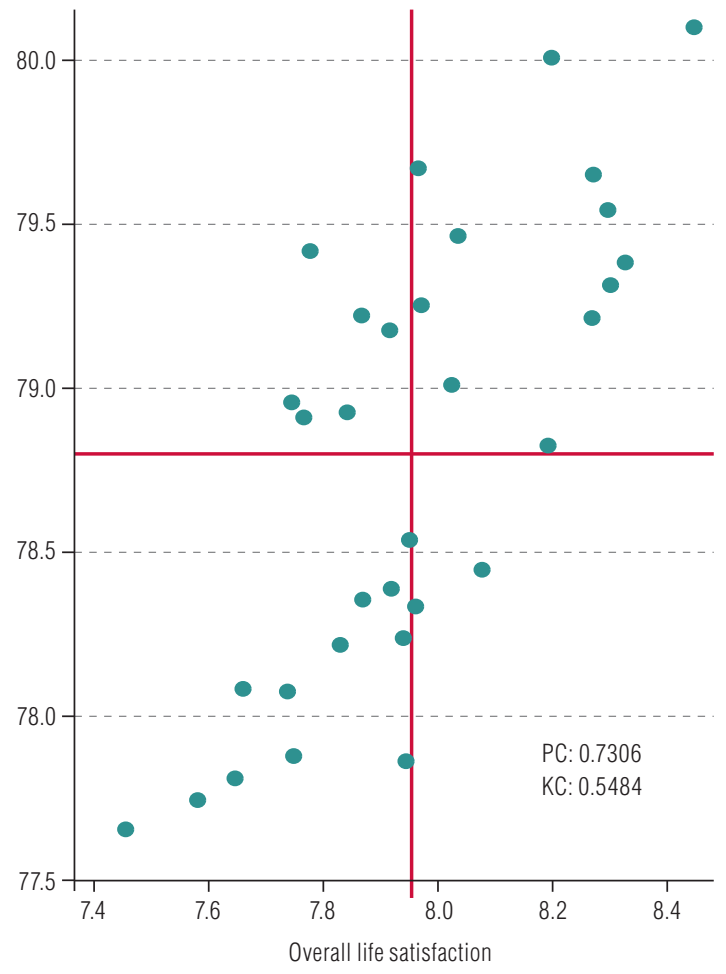

— Mean of indicator

Source: Prepared by the authors, on the basis of official data from the National Institute of Statistics and Geography (INEGI), the United Nations Development Programme (UNDP) and the Organization for Economic Cooperation and Development (OECD).

Note: PC: Pearson correlation; KC: Kendall's tau coefficient. 
Firstly, the Pearson correlation coefficient presented in figure 3 shows that both indicators have a positive relationship with the $I M B E_{i}$, in other words a rise in one indicator is related to a rise in the other; this relationship is much more marked in the case of the human development index. On the other hand, Kendall's tau coefficient of correlation indicates that the rank correlation between the indicators is not that high, that is to say the variation in state well-being is not regular for the two indicators considered in each case. The positions occupied by each state differ for each indicator, especially in comparison with the indicator of self-reported well-being. Thus far, it can be argued that these results confirm the importance of income in the overall well-being of the Mexican population, and they appear to support various studies' findings regarding the low importance of income in individuals' subjective well-being.

Regarding the indicators adapted from other approaches, the proposal of Bérenger and Verdier-Chouchane (2007) was taken into account (see table 1), adding the self-reported well-being dimension to perform a more suitable comparison ${ }^{5}$ with the $I M B E_{i}$; as mentioned, this index is called $S o L_{i}$ because it is based on the dimensions of these authors' standards of living indicator. The dimensions, indicators ${ }^{6}$ and process ${ }^{7}$ used to construct the OECD global well-being index (2015) were also employed, but instead of using the Adjusted Mazziotta-Pareto Indices (AMPI) to construct the dimensions ${ }^{8}$ and the overall well-being index, the same methodology used to obtain $I M B E_{i}$ was applied, namely factor analysis to obtain statistically different weights by dimension and indicator; this index was named $B L I_{i}$, because it refers to data regarding the Better Life Index. For a more complete comparison, the 2014 index reported by OECD (2015) is also shown, simply referred to as the AMPI indicator.

As regards calculation of the indices, in the case of the $S o L_{i}$ index the indicators were assigned a similar weight (around 10\%) through the factor analysis method; the lowest weights were those of life satisfaction (almost 8\%) and health status (9.3\%), while the highest was that for disposable income, at 13\%. In the construction of the $B L I_{i}$ index the dimensions with the highest weights were environment (9\%) and health (8.84\%); The lowest weights were, apart from civic and political engagement (2.42\%), those of the dimensions relating to subjective well-being: life satisfaction (3.73\%), work-life balance (4.78\%) and social connections (5.12\%). Having obtained the weighting factors for each dimension, the respective indices were constructed, as presented in table 8.

Table 8 shows the value of each well-being indicator, as well as the rank of each state for each indicator. All indicators of well-being, except that of life satisfaction (BIARE), place Baja California Sur, Nuevo León and Sonora among the five states with the greatest well-being, and Chiapas, Guerrero, Oaxaca and Puebla among those with the lowest well-being. For their part, the $I M B E_{i}, S_{O} L_{i}$ and $\mathrm{HDI}$ indicators place the states at essentially the same well-being rank, with Mexico City and Nuevo León again among the best, and Chiapas and Oaxaca among the worst.

5 The reliability tests found that the Gini coefficient of disposable income indicator, in addition to not contributing to the underlying scale of Cronbach's alpha, did not have a significant correlation with any other indicator, so it was not considered in the construction of the index; in this regard, tests were performed to verify reliability and fulfilment of the assumptions of the factor analysis by omitting this indicator, and no problem was found.

6 The most recent indicators available in the INEGI Better Life Index are considered. The indicators taken from the Self-Reported Well-Being Module, unlike those used by OECD (2015), are representative at the state level. To construct the dimensions, indicators whose relationship with well-being was negative (such as the poverty indicator) were transformed (multiplicative inverse) so that they all had a positive relationship with well-being.

7 This refers to the two stages in the construction of the global well-being index. In the first stage the dimensions are constructed from the corresponding indicators, and in the second stage the index is constructed from the dimensions obtained. Factor analysis was used in both cases.

8 For the states of Michoacán, Oaxaca and Sonora, the education dimension was constructed without using information from the Programme for International Student Assessment (PISA), because data was not available. 
Table 8

Mexico: well-being indicators for states

\begin{tabular}{|c|c|c|c|c|c|c|c|c|c|c|c|c|}
\hline \multirow{2}{*}{ State } & \multicolumn{2}{|c|}{ IMBE 2014} & \multicolumn{2}{|c|}{ BLI 2014} & \multicolumn{2}{|c|}{ SoL 2014} & \multicolumn{2}{|c|}{ AMPI 2014} & \multicolumn{2}{|c|}{ HDI 2012} & \multicolumn{2}{|c|}{ BIARE 2014} \\
\hline & Value & Rank & Value & Rank & Value & Rank & Value & Rank & Value & Rank & Value & Rank \\
\hline Aguascalientes & 78.95 & 15 & 109.95 & 12 & 100.19 & 14 & 103.7 & 11 & 0.7595 & 9 & 7.74 & 27 \\
\hline Baja California & 79.65 & 4 & 110.02 & 8 & 101.18 & 4 & 102.3 & 12 & 0.7598 & 8 & 8.27 & 5 \\
\hline Baja California Sur & 79.54 & 5 & 110.32 & 2 & 101.25 & 3 & 109.4 & 1 & 0.7762 & 4 & 8.29 & 4 \\
\hline Campeche & 78.91 & 17 & 109.38 & 19 & 100.02 & 15 & 98.2 & 20 & 0.7490 & 15 & 7.76 & 25 \\
\hline Mexico City & 80.10 & 1 & 110.03 & 7 & 102.05 & 1 & 100.1 & 15 & 0.8300 & 1 & 8.44 & 1 \\
\hline Chiapas & 77.86 & 29 & 108.84 & 28 & 98.49 & 31 & 90 & 30 & 0.6672 & 32 & 7.94 & 16 \\
\hline Chihuahua & 79.38 & 8 & 109.87 & 14 & 100.39 & 11 & 102.3 & 13 & 0.7344 & 19 & 8.32 & 2 \\
\hline Coahuila & 79.46 & 6 & 110.08 & 5 & 100.77 & 6 & 105.7 & 6 & 0.7682 & 5 & 8.03 & 10 \\
\hline Colima & 79.41 & 7 & 110.10 & 4 & 100.49 & 10 & 107.4 & 3 & 0.7631 & 6 & 7.77 & 24 \\
\hline Durango & 78.82 & 18 & 109.74 & 17 & 99.84 & 19 & 102.1 & 14 & 0.7309 & 21 & 8.19 & 8 \\
\hline State of Mexico & 78.35 & 22 & 109.08 & 23 & 99.92 & 17 & 94.5 & 26 & 0.7445 & 16 & 7.86 & 20 \\
\hline Guanajuato & 78.23 & 24 & 109.35 & 20 & 99.51 & 23 & 95.5 & 24 & 0.7197 & 26 & 7.93 & 17 \\
\hline Guerrero & 77.87 & 28 & 108.73 & 30 & 98.64 & 30 & 86 & 32 & 0.6794 & 31 & 7.74 & 26 \\
\hline Hidalgo & 78.33 & 23 & 108.91 & 27 & 99.46 & 24 & 95.5 & 25 & 0.7229 & 24 & 7.96 & 14 \\
\hline Jalisco & 78.92 & 16 & 110.02 & 9 & 100.21 & 13 & 104.4 & 9 & 0.7514 & 13 & 7.84 & 22 \\
\hline Michoacán & 77.81 & 30 & 109.00 & 26 & 98.90 & 29 & 98.3 & 19 & 0.7001 & 29 & 7.64 & 30 \\
\hline Morelos & 78.08 & 26 & 109.02 & 25 & 99.51 & 22 & 93.5 & 28 & 0.7494 & 14 & 7.66 & 29 \\
\hline Nayarit & 79.17 & 13 & 109.99 & 10 & 99.98 & 16 & 105.6 & 8 & 0.7330 & 20 & 7.91 & 19 \\
\hline Nuevo León & 80.00 & 2 & 110.95 & 1 & 101.46 & 2 & 107.6 & 2 & 0.7896 & 2 & 8.19 & 7 \\
\hline Oaxaca & 77.65 & 32 & 108.54 & 32 & 98.30 & 32 & 87.9 & 31 & 0.6813 & 30 & 7.45 & 32 \\
\hline Puebla & 77.74 & 31 & 108.72 & 31 & 98.93 & 28 & 93.2 & 29 & 0.7171 & 27 & 7.58 & 31 \\
\hline Querétaro & 79.21 & 12 & 109.84 & 13 & 100.59 & 9 & 103.8 & 10 & 0.7601 & 7 & 8.26 & 6 \\
\hline Quinta Roo & 79.25 & 10 & 109.88 & 15 & 100.64 & 8 & 100.1 & 16 & 0.7536 & 12 & 7.97 & 12 \\
\hline Sinaloa & 79.22 & 11 & 110.07 & 6 & 100.25 & 12 & 106.4 & 5 & 0.7574 & 11 & 7.86 & 21 \\
\hline San Luis Potosí & 78.53 & 19 & 109.31 & 21 & 99.65 & 20 & 98.2 & 21 & 0.7262 & 23 & 7.95 & 15 \\
\hline Sonora & 79.67 & 3 & 110.17 & 3 & 101.08 & 5 & 106.6 & 4 & 0.7792 & 3 & 7.96 & 13 \\
\hline Tabasco & 78.38 & 21 & 109.07 & 24 & 99.57 & 21 & 96.3 & 22 & 0.7416 & 17 & 7.91 & 18 \\
\hline Tamaulipas & 79.31 & 9 & 109.97 & 11 & 100.70 & 7 & 105.7 & 7 & 0.7580 & 10 & 8.30 & 3 \\
\hline Tlaxcala & 78.21 & 25 & 109.26 & 22 & 99.30 & 26 & 94.2 & 27 & 0.7271 & 22 & 7.82 & 23 \\
\hline Veracruz & 78.07 & 27 & 108.80 & 29 & 99.05 & 27 & 96 & 23 & 0.7134 & 28 & 7.73 & 28 \\
\hline Yucatán & 79.01 & 14 & 109.83 & 16 & 99.90 & 18 & 99.4 & 18 & 0.7393 & 18 & 8.02 & 11 \\
\hline Zacatecas & 78.44 & 20 & 109.43 & 18 & 99.30 & 25 & 100.1 & 17 & 0.7200 & 25 & 8.07 & 9 \\
\hline
\end{tabular}

Source: Prepared by the authors, on the basis of data from the National Institute of Statistics and Geography (INEGI), the United Nations Development Programme (UNDP) and the Organization for Economic Cooperation and Development (OECD).

Note: IMBE: multidimensional index of well-being at state level; BLI: well-being index based on the OECD Better Life Index (2015); SoL: well-being index based on the standards of living of Bérenger and Verdier-Chouchane (2007); AMPI: Adjusted Mazziotta-Pareto Index for 2014 as reported by OECD (2015); HDI: human development index; BIARE: life satisfaction indicator from the INEGI Self-Reported Well-being Module.

Figure 4 provides a clearer picture of the similarities and differences between the adapted indices and the AMPI indicator. Naturally, the greatest correlation is between $I M B E_{i}$ and $S o L_{i}$. This is no surprise, since $I M B E_{i}$ differs only from $S o L_{i}$ in that it includes more indicators of subjective well-being, which had relatively lower weights in construction of the index. However, the correlation between $I M B E_{i}$ and the $B L I_{i}$ index is more interesting, given the significant differences in their construction; although they do not include the same number of dimensions and consider different quantities of indicators with distinct characteristics (except the objective or subjective characteristics of well-being), the correlation between the two is very high. Even when considering Kendall's tau coefficient, the two indices rank the different states by well-being almost identically. 


\section{Figure 4}

Mexico: relationship between different well-being indicators, 2014

A. IMBE and BLI indicators

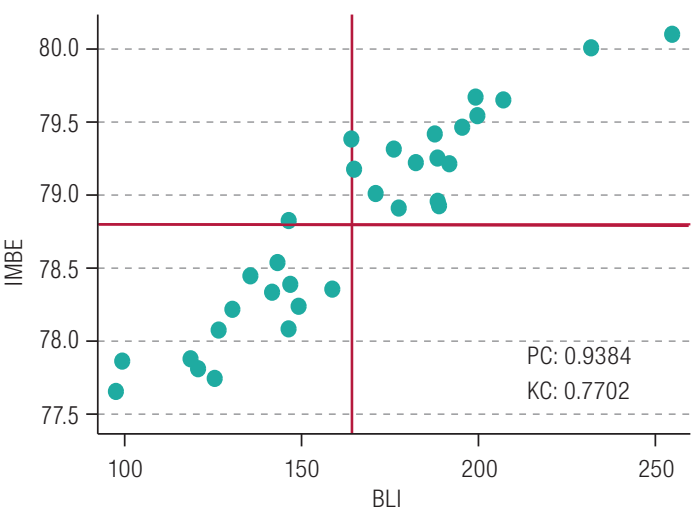

C. IMBE and AMPI indicators

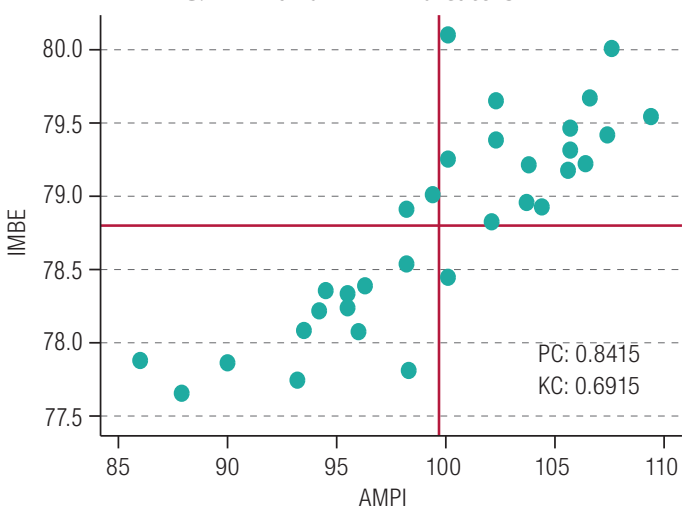

B. IMBE and SoL indicators

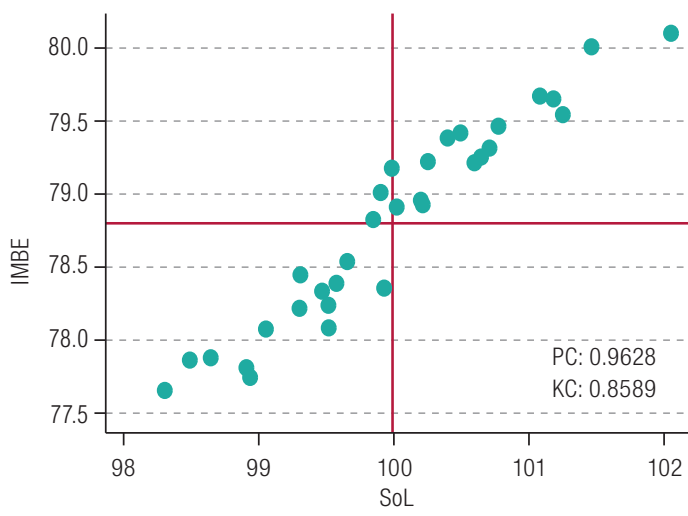

D. BLI and AMPI indicators

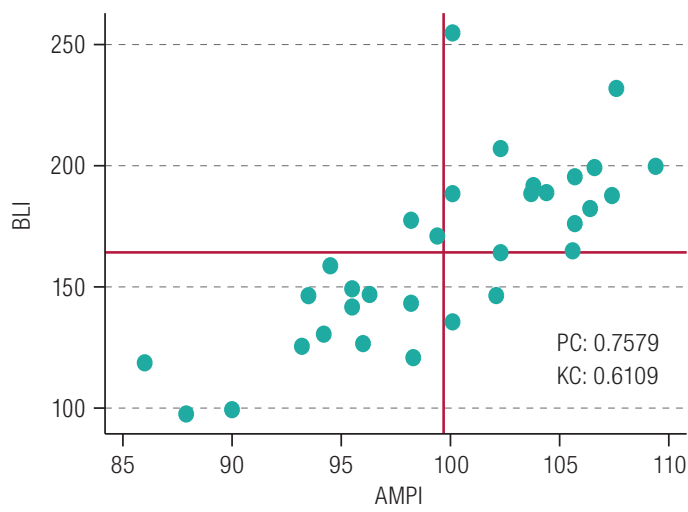

— Mean of indicator

Source: Prepared by the authors, on the basis of official data from the National Institute of Statistics and Geography (INEGI) and the Organization for Economic Cooperation and Development (OECD).

Note: $\quad$ IMBE = multidimensional index of well-being at state level; BLI = well-being index based on the OECD Better Life Index (2015); SoL = well-being index based on the standards of living of Bérenger and Verdier-Chouchane (2007); AMPI = Adjusted Mazziotta-Pareto Index for 2014 as reported by the OECD (2015).

$\mathrm{PC}=$ Pearson correlation; $\mathrm{KC}=$ Kendall's tau coefficient.

Upon comparison, as shown in figure 4, although positive variations in any indicator are related to positive variations in the AMPI, there is a significant difference in the positioning they take with respect to well-being of the states; even the $B L I_{i}$ index, which comprises essentially the same data as the AMPI index, shows considerable differences, as it allows for different weights of indicators and dimensions in overall well-being. The most noteworthy case is that of Mexico City, which in all indicators ranks number 1 for well-being, except in AMPI and $B L I_{i}$, where it is close to the mean (positions 15 and 7 , respectively). In fact, it is this difference in Mexico City's well-being indicators that "penalizes" the correlation in figures 4C and 4D; the difference is explained by the fact that this state is ranked among the lowest in dimensions of subjective well-being, specifically in indicators of life satisfaction and work-life balance, and since these dimensions are more important in the AMPI than in the $I M B E_{i}$ or the $B L I_{i}$, the overall well-being value for Mexico City is much lower in the case of the AMPI. This clear difference between $B L I_{i}$ and AMPI, and the similarity between $B L I_{i}$ and $I M B E_{i}$, reaffirm the importance of considering sensitivity to weights when constructing indicators (Stiglitz, Sen and Fitoussi, 2009), even more so than the choice of variables, at least in the case of these indicators of well-being. 


\section{Conclusions}

The fact that Mexico is the fifteenth largest economy in the world in terms of gross domestic product (GDP) (according to World Bank data for 2015) and that more than half of its inhabitants are living in poverty shows just how complex it is to establish policies to improve well-being, at least in the short term, reflecting a conflict between economic growth and reductions in poverty and inequality (López, 2004). In the same vein, it is indisputable that a public policy to improve the well-being of the population that considers the components of well-being in isolation will achieve only limited success or fail entirely. Therefore, there is an inescapable need to consider various objective and subjective aspects when constructing well-being indicators, as stated in theory; in this regard, Stiglitz, Sen and Fitoussi (2009) make the most significant contribution concerning theoretical and practical recommendations for construction of such indicators.

Despite additional complications concerning measurement of subjective aspects of well-being, important progress has recently been made in Mexico through the INEGl self-reported well-being project, providing information on the overall well-being of the population at the national and state levels and insight into the relationships between the different dimensions of well-being. As a result of this information, noteworthy advances have also been made in construction of indicators of overall well-being, in addition to the human development index and the poverty indicators of the National Council for the Evaluation of Social Development Policy (CONEVAL); of these indicators, the most recent is that of OECD (2015), which, by including 35 indicators relating to 12 dimensions of well-being, considers complex and vast information regarding the overall well-being status of the Mexican population. However, this indicator does not attach importance to the weight of each dimension in the overall level of well-being, nor does it use subjective well-being indicators that are representative at the state level, and it ascribes little relevance to inequality, casting doubt on the suitability of making decisions based on its information. At the individual level, it is also reasonable to say that the different facets of well-being may differ in importance, since there is clear heterogeneity in the Mexican population in terms of income, education, access to services, time spent on work, leisure or culture, among other aspects. It is even possible to attribute some truth to the Maslowian position, in the sense of fundamentally allocating the material dimensions of well-being, such as access to food or health, with higher weights than other dimensions such as participation in social groups or living in a situation with lower levels of corruption.

This study therefore adapts a multidimensional well-being index to address the weaknesses identified in the OECD indicator, based on the recommendations of Stiglitz, Sen and Fitoussi (2009). If a purely statistical methodology is employed, the criticism of value judgments on the relative importance of each dimension is avoided, but there is still potential for such a differentiation in their weights. In addition, consideration of the approaches provided by other studies (Bérenger and Verdier-Chouchane, 2007; OECD, 2015) makes it possible to analyse the importance of including different weights, dimensions and indicators when constructing the well-being index. In this sense, the results show that the greatest differences appear when different weights are assigned to the dimensions, supporting the argument that they each have a different impact on well-being; even the possibility of changing weights is more important than selection of the indicators or dimensions themselves.

Another aspect that is evident is the relative importance of the dimensions and indicators related to material well-being, since in all cases they were more important than those related to subjective well-being; in this regard, it can be argued that these results highlight the validity of the human development index as an indicator of the well-being of the Mexican population. But this does not mean that subjective well-being is not important in the analysis. All the same, in the Mexican case, material well-being is perhaps more linked to other dimensions of well-being and, therefore, should be addressed as a priority. It is also important to note that, although a correlation analysis is performed, the question of causality between the dimensions of well-being is not addressed and therefore no conclusions can 
be drawn as to whether indicators related to the dimension of material well-being (such as income) have a positive effect on subjective well-being. Until a conclusion can be reached, in a country where around half of the population suffers from some form of poverty, it would perhaps be more appropriate to have a well-being indicator that assigns a higher weight to scarcity of material goods.

Another aspect to consider is that, in order to enable comparison between states, as a starting point for each state dimensions are all weighted in the same way; returning to the argument regarding heterogeneity, this could be said to be a limiting factor of this study, since regional and state differences can be expected. For example, it can be argued that the population of southern states obtains well-being associated with environmental indicators that differs from that obtained by the population in areas where natural resources are scarce, such as Mexico City or the northern states. In this respect, analysis at the microdata level could provide information on the existence of differences in weighting of the dimensions between states, but that is beyond the scope of this study.

\section{Bibliography}

Aiginger, K. and M. Firgo (2015), "Regional competitiveness under new perspectives", Policy Paper, No. 26, Vienna, WWW for Europe.

Arita, B. (2005), "La capacidad y el bienestar subjetivo como dimensiones de estudio de la calidad de vida", Revista Colombiana de Psicología, vol. 14, Bogotá, National University of Colombia.

Beckley, H. (2002), "Capability as opportunity: how Amartya Sen revises equal opportunity", Journal of Religious Ethics, vol. 30, No. 1, Hoboken, Wiley.

Bentham, J. (2000), An Introduction to the Principles of Morals and Legislation, Kitchener, Batoche Books.

Benvin, E., E. Rivera and V. Tromben (2016), "A multidimensional time use and well-being index: a proposal for Colombia, Ecuador, Mexico and Uruguay”, CEPAL Review, No. 118 (LC/G.2676-P), Santiago, Economic Commission for Latin America and the Caribbean (ECLAC).

Bérenger, V. and A. Verdier-Chouchane (2007), "Multidimensional measures of well-being: standard of living and quality of life across countries", World Development, vol. 35, No. 7, Amsterdam, Elsevier.

Bonini, A. (2008), "Cross-national variation in individual life satisfaction: effects of national wealth, human development, and environmental conditions", Social Indicators Research, vol. 87, No. 2, New York, Springer.

Chakravarty, S. and M. Lugo (2016), "Multidimensional indicators of inequality and poverty", The Oxford Handbook of Well-being and Public Policy, M. Adler and M. Fleurbaey (eds.), New York, Oxford University Press.

Graham, J. (2006), "Congeneric and (essentially) tau-equivalent estimates of score reliability: what they are and how to use them", Educational and Psychological Measurement, vol. 66, No. 6, Thousand Oaks, SAGE.

Hicks, D. (2002), "Gender, discrimination, and capability: insights from Amartya Sen", The Journal of Religious Ethics, vol. 30, No. 1, Hoboken, Wiley.

Kaiser, H. (1974), "An index of factor simplicity", Psychometrika, vol. 39, No. 1, New York, Springer.

Kolm, S. (1997), Justice and Equity, Cambridge, MIT Press.

Krauss, A. and C. Graham (2013), "Subjective wellbeing in Colombia: some insights on vulnerability, job security, and relative incomes", Policy Research Working Paper, No. 6672, Washington, D.C., World Bank.

Lever, J. (2004), "Poverty and subjective well-being in Mexico", Social Indicators Research, vol. 68, No. 1, New York, Springer.

López, J. (2004), "Pro-growth, pro-poor: is there a trade-off?", Policy Research Working Paper, No. 3378, Washington, D.C., World Bank.

Mexico, Government of (2013), Plan Nacional de Desarrollo 2013-2018, Mexico City.

Nafziger, E. (2005), Economic Development, Cambridge, Cambridge University Press.

OECD (Organization for Economic Cooperation and Development) (2015), Measuring Well-being in Mexican States, Paris, OECD Publishing.

(2014), How's Life in Your Region? Measuring Regional and Local Well-being for Policy Making, Paris, OECD Publishing.

(2008), Handbook on Constructing Composite Indicators. Methodology and User Guide, Paris, OECD Publishing. 
Plata, L. (1999), "Amartya Sen y la economía del bienestar", Estudios Económicos, vol. 14, No. 1, Mexico City, El Colegio de México.

Rawls, J. (1971), A Theory of Justice, Cambridge, Harvard University Press.

Rojas, M. (2007), "The complexity of well-being: a life-satisfaction conception and a domains-of-life approach", Well-being in Developing Countries: from Theory to Research, I. Gough and J. McGregor (eds.), New York, Cambridge University Press.

(2005), “¿Qué es desarrollo económico?”, La formación de economistas: ensayos en honor de Pepita Echandi, J. Vargas and Y. Xirinachs (eds.), San José, University of Costa Rica.

Sen, A. (1984), Resources, Values, and Development, Cambridge, Harvard University Press.

StataCorp (2013), Stata Multivariate Statistics Reference Manual: Release 13, College Station, StataCorp LP.

Stiglitz, J., A. Sen and J. Fitoussi (2009), Report by the Commission on the Measurement of Economic Performance and Social Progress, Paris, The Commission.

Tavakol, M. and R. Dennick (2011), "Making sense of Cronbach's alpha", International Journal of Medical Education, vol. 2, Nottingham, Mayfair Publications.

Thomson, W. (2016), "Fair allocation", The Oxford Handbook of Well-being and Public Policy, M. Adler and M. Fleurbaey (eds.), New York, Oxford University Press.

Valencia, G. and J. Cuervo (1999), "Crítica a las bases éticas de la teoría neoclásica en la propuesta del bienestar social de Amartya Sen", Lecturas de Economía, No. 51, Medellín, University of Antioquia.

Veenhoven, R. (2005), "Is life getting better? How long and happy people live in modern society", European Psychologist, vol. 10, No. 4, Boston, Hogrefe.

Villatoro, P. (2012), "La medición del bienestar a través de indicadores subjetivos: una revisión", Estudios Estadísticos y Prospectivos series, No. 79 (LC/L.3515), Santiago, Economic Commission for Latin America and the Caribbean (ECLAC).

Wells, T. (2016), "Sen's capability approach", Internet Encyclopedia of Philosophy, J. Fieser and B. Dowden (eds.), Martin, University of Tennessee at Martin.

Yurdugül, H. (2008), "Minimum sample size for Cronbach's coefficient alpha: a Monte-Carlo study", Hacettepe University Journal of Education, vol. 35, Beytepe, Hacettepe University. 


\section{Annex A1}

The OECD Handbook on Constructing Composite Indicators (2008) includes 10 steps: (i) development of the theoretical framework, (ii) data selection, (iii) imputation of missing data, (iv) multivariate analysis, (v) normalization, (vi) weighting and aggregation, (vii) sensitivity analysis, (viii) data screening, (ix) links to other indicators and $(x)$ visualization of results. This article primarily addresses the technical recommendations of the fourth and sixth steps concerning factor analysis of principal components and Cronbach's alpha.

The OECD (2008) mentions that Cronbach's alpha is not a statistical test but a coefficient of reliability (internal consistency) based on the correlation between individual indicators. Thus, high correlation indicates that individual indicators measure the same underlying variable or dimension, in this case well-being. It should be noted that although calculation of Cronbach's alpha allows the value of a scale to be obtained for each observation, using this scale as the underlying variable or dimension can lead to flawed conclusions. In this regard, some authors (such as Graham (2006) and Tavakol and Dennick (2011)) stress that Cronbach's alpha should not be considered a uni-dimensional test, as it can be misleading if the underlying scale considers more than one dimension. Therefore, Tavakol and Dennick (2011) suggest using factor analysis to identify more than one dimension in a test.

Thus, considering that the scale obtained through Cronbach's alpha is multidimensional, the suggestion of Tavakol and Dennick (2011) and OECD (2008) is followed, using factor analysis of principal components to construct the well-being indicator according to the weights obtained through this same method; although there are other approaches such as the axiomatic method and fuzzy set theory (Chakravarty and Lugo, 2016), factor analysis of principal components is easily applied and offers advantages in terms of interpretation of its results. To this end, OECD (2008) states that it is necessary to have relatively high correlation between the original variables $x_{i j}$; otherwise, it would not make sense to apply this approach. Therefore, after calculating Cronbach's alpha, correlation analysis of the $x_{i j}$ variables is performed to confirm that the relationships are statistically significant and have the expected sign, and to examine the groups of variables with the closest relationship that may be found at the time of the factor analysis.

After confirming the existence of significant correlations between the variables of interest, a factor analysis of principal components is performed to obtain $W_{k}$ and $w_{j k}$, used in equation (1), validated by means of the Kaiser-Meyer-Olkin measure. According to the OECD criteria (2008), the principal components are considered if they satisfy three conditions: (i) they are orthogonal and contribute at least $10 \%$ to the explanation of overall variance; (ii) they contain the largest proportion of variance accounted for with an eigenvalue of more than 1; (iii) they contribute cumulatively to the explanation of the overall variance by more than $60 \%$. Subsequently, the weights are obtained from the squares of factor loadings normalized by the variance of the factor. These normalized weights are obtained from the rotated factors by means of the varimax method, in order to minimize the number of indicators in each factor and to have a simpler compositional structure of the factors used; in other words, this varimax rotation method transforms the original loadings (without rotation) without affecting the variance of the factors to improve their interpretation (StataCorp, 2013) and to facilitate the calculations in equation (1). 